\title{
Correction to: Adhesive connections in glass structures-part II: material parameter identification on thin structural silicone
}

\author{
Michael Drass $\mathbb{D}$ - Gregor Schwind • \\ Jens Schneider · Stefan Kolling
}

Published online: 13 December 2017

(C) Springer International Publishing AG, part of Springer Nature 2017

Correction to: Glass Struct. Eng. https://doi.org/10.1007/s40940-017-0048-3

The name of the second author contained a typing error.

The original article has been corrected.

The original article can be found online at https://doi.org/10. 1007/s40940-017-0048-3.

M. Drass $(\varangle) \cdot$ G. Schwind $\cdot$ J. Schneider

Institute of Structural Mechanics and Design, Technische

Universität Darmstadt, Darmstadt, Germany

e-mail: drass@ismd.tu-darmstadt.de

G. Schwind

e-mail: gregor_schwind2k@hotmail.com

J. Schneider

e-mail: schneider@ismd.tu-darmstadt.de

S. Kolling

Institute of Mechanics and Materials, Technische

Hochschule Mittelhessen, Giessen, Germany

e-mail: stefan.kolling@me.thm.de 